proved groundless, and possibly one of the greatest services that the Institute has rendered to the industry is the breaking down of such prejudice and by providing a bridge across which scientific men and practical men can come into contact. The work of Shaw Scott, the first secretary and editor, received from the new president, who is in a position personally to appreciate his work, the fullest and most welldeserved praise. To Shaw Scott's guidance and devotion the Institute owes much. Among the papers read at the opening meeting in Birmingham in November 1908, Echavarri spoke of aluminium and its uses, and referred to the "enormous" demand for aluminium in 1906 and 1907 when the world production was 15,000 and 23,600 tons respectively; these figures are interesting in comparison with that of $1,890,000$ tons a year at the peak of production during the Second World War.

The concluding part of the address was devoted to the future. As one concerned with both the metallurgical and the chemical industries, Sir Arthur contrasted the essentially continuous processes char. acteristic of the chemical industry with the 'batch' process normal in non-ferrous metal production. "To any industrial metallurgist laying down a new plant, I would commend the technical approach of the industrial chemist as worthy of close consideration." This represents the crux of the plea made for the reduction or, if possible, complete elimination of 'idle time'. Coming from one who is essentially an industrialist, it is of the greatest interest that he pleaded for the encouragement "of those who are engaged on investigations which may at present be of little or no commercial value, but which are calculated to establish the underlying general principles of the science of metallurgy". As an instance of what can be done in this direction, the aluminium light-alloy industry was quoted as a practical example.

\section{The Royal Air Force School of Education}

A NEw Royal Air Force School of Education has been opened at Wellesbourne Mountford, near Leamington Spa, and one of its main purposes is to prepare newly appointed education officers for their professional duties in the R.A.F. The School is housed for the present in temporary accommodation because in view of the nature and the importance of the work a start could not be delayed. It is intended, however, to move the School to a more permanent location when this is feasible. Education in the R.A.F. differs little in its background from education in the civilian world. Its immediate purpose is to develop those qualities of mind and char. acter which, while adapting the officer, the airman or the boy apprentice to the exercise of particular duties, yet helps him to achieve a worthwhile personal and social life and to appreciate the duties and privileges of citizenship. On the technical side, too, it is the task of the Education Branch to contribute a theoretical content towards technical and air-crew training of R.A.F. personnel for their day-to-day duties. Naturally the means and conditions through which these tasks are performed in the Service so far differ from those outside as to involve the young education officer in a period of some difficulty until he finds his feet. It is a function of this new school of education to minimize this period, and to orientate the professional qualifications and experience of the newly appointed officer (normally a university graduate and a trained teacher, and preferably with some initial teaching experience) towards his now duties.
To this end he is given instruction over a period of four weeks in the organisation and administration of R.A.F. education, in certain aspects of the theory and practice of Service teaching, in the part played by education in maintaining high standards of training and of morale, and in the methods to be employed for education in citizenship and current affairs. In addition to the lectures given by the permanent staff provision is made in the School programme for visiting lecturers of eminence in the civilian world.

It will be noted that the School lays emphasis on the scheme for the education of Service personnel in citizenship and current affairs. Indeed the School will play a part of growing significance in the further development of this scheme, and in the near future a series of courses will begin at Wellesbourne Mount. ford which are designed for the benefit of officers of branches other than education who may volunteer to assist in the running of discussion groups on their stations. These courses will train the officers in the technique of discussion-group leadership, and will include a factual background in citizenship and current affairs. Until the machinery of recruitment gets into its full stride, there will for some little time ahead be an acute shortage of education officers in the R.A.F. As a temporary expedient, suitable officers and others of the Service who have lesser qualifications but a liking for the work, and who volunteer for temporary duty in the Education Branch, will be accepted for duty as educational assistants-and to prepare them for this work special short courses are to be arranged for them at Wellesbourne Mountford almost immediately. They will follow the lines of the main course as for education officers, but on a somewhat lower plane. In the case of airmen volunteers, since they will be given acting non. commissioned officer rank on the successful completion of the course, training will also be given in disciplinary and other duties appropriate to the rank. Finally, it is intended that the School will, from time to time, provide specialized courses of a refresher nature to keep education officers up to date in the development of new educational techniques and of educational research.

\section{Conference on Scientific Information Services}

THe Royal Society is arranging a Conference on Scientific Information Services to be held in London during June 21-July 2. The Conference, which will consider information services from the point of view of the scientific user, in accordance with the recom. mendation made in 1946 by the Royal Society Empire Scientific Conference and the British Commonwealth Scientific Official Conference, will be attended by representatives of countries providing information services in English. Editors-in-chief, who will prepare memoranda as bases of discussion, have been ap. pointed as follow for the four sections into which the Conference will be divided: Section 1, publication and distribution of papers reporting original work (Prof. J. D. Bernal) ; Section 2, abstracting services (Sir David Chadwick) ; Section 3, indexing and other library services (Dr. J. E. Holmstrom); Section 4, reviews, annual reports, etc. (Prof. H. Munro Fox). It is hoped to cover all scientific subjects, including agricultural, medical and engineering sciences. Material suggested for discussion should be submitted as soon as possible to the appropriate editor-in-chief c/o Assistant Secretary, Royal Society, Burlington House, London, W.1. Contributors are asked to 